\title{
Phytochemical Screening and Antioxidative Potentials of "Beach Morning Glory" Ipomoea pes- caprae (Linn.) Roth Leaves Extract
}

\author{
Victoria E. Matunog ${ }^{1}$ and Lydia M. Bajo ${ }^{2}$ \\ ${ }^{1}$ Natural Science Department, College of Arts and Sciences, Misamis University, \\ Ozamiz City, Philippines \\ ${ }^{2}$ Department of Chemistry, College of Science and Mathematics, MSU-Iligan Institute \\ of Technology, Iligan City, Philippines \\ Corresponding email: victoria_elcano@yahoo.com.ph
}

\begin{abstract}
Ipomoea pes-caprae (Linn.) Roth, or beach morning glory, is a mangrove associate medicinal plant species of Convolvulaceae family that favorably grows in tropical and subtropical countries. Previous phytochemical screening revealed the presence of pharmacologically active components which could differ according to environmental conditions. In the Philippines, evidences on extensive investigation of the plant are not yet available. This study aimed to conduct phytochemical screening, and antioxidative potential determination of the dried leaves aqueous ethanol extract of I. pes-caprae (Linn.) Roth. Exhaustive serial extraction apportioned the crude ethanol extract (CEE) into hexane extract (HE); ethyl acetate extract (EAE); methanol extract (ME) and aqueous extract (AE). Ferric thiocyanate (FTC) assay determined the antioxidative potentials of CEE and the four serial extracts. The positive controls used in FTC assay were Vitamin E and butylated hydroxyl toluene (BHT). Phytochemical screening of CEE showed the presence of alkaloids; flavonoids; steroids and triterpenes; and tannins and phenolic compounds. FTC assay on CEE showed antioxidative activity but of lower extent than vitamin E and BHT. For serial extracts, FTC assay revealed that $\mathrm{ME}$ and $\mathrm{AE}$ possessed antioxidative activity comparable to vitamin E and BHT. These results showed that the wildly grown I. pescaprae is a potential source of pharmacologically active phytochemicals specifically the antioxidants.
\end{abstract}

Keywords: Convolvulaceae, ferric thiocynate assay, mangrove, pharmacologically active, serial extraction 


\section{Introduction}

Ipomoea pes-caprae (Linn.) Roth, or beach morning glory, is a mangrove associate medicinal plant species of Convolvulaceae family that favorably grows in tropical and subtropical countries. This plant stabilized sand dunes and prevented coastal erosion (Hill, 2001) and used in folk remedies for different types of ailments (Ganjir et al., 2013). Pharmacological profiling of the plant showed the following activities: antioxidant (Ramanathan et al., 2012; Parekh et al., 2012), analgesic (De Souza et al., 2000; Bragadeeswaran et al., 2010; Rajamoni, 2010; Vieira et al., 2012), anti-inflammatory (Vieira et al., 2012; Venkataraman et al., 2013a; Pongprayoon et al., 2006), antispasmodic (Pongprayoon et al., 1992), antinociceptive (Vieira et al., 2012; Krogh et al., 1999; De Souza et al., 2000), antiarthritic (Venkataraman et al., 2013b), antihistaminic (Wasuwat, 1970), insulinogenic and hypoglycemic activities (Khan et al., 1994), antifungal - Candida albicans and Microsporum audouinni (Ramanathan et al., 2011) and immunostimulatory (Philippi et al., 2010).

Phytochemical screening of I. pes-caprae extracts has also revealed the presence of pharmacologically active components. Methanol extracts from leaves contain saponins and tannins (Ganjir et al., 2013). The aqueous methanol extract of the aerial part contains steroids, terpenoids, alkaloids, flavonoids (De Souza et al., 2000) and exceptionally, high phenolic compounds (Banerjee et al., 2008). Both leaves and stem ethanol extracts contain alkaloids, saponins, tannins, anthraquinones and flavonoids (Venkataraman et al., 2013b). Phytochemicals are secondary metabolites, which exhibit protective or disease preventive properties (Murugan et al., 2013). Terpenoids and alkaloids exhibit hypoglycemic activities; steroids and triterpenoids as analgesics; saponins as antioxidant and anti-inflammatory; and flavonoids show anti-allergic, anti-inflammatory, antimicrobial and anticancer activities (Wani et al., 2012). The phenolics such as flavonoids, phenolic acids and tannins, exhibit largely antioxidative property and diverse biological activities in plant (Li, 2009).

However, few studies on I. pes-caprae revealed some contradicting results. Pharmacological profiling of methanol extract from the aerial parts of the plant, in Florianopolis, Brazil, did not 
exhibit antispasmodic activity (Emendörfer et al., 2005). This area has a warm humid temperate climate with hot summers and no dry season (Weather Spark beta, 2012). Conversely, Pongprayoon et al. (1992) in Sweden, had isolated antispasmodically acting isoprenoids betadamascenone and E-phyto. Most parts of Sweden are icebound in winter, but experience elevated temperature ranging from $13^{0} \mathrm{C}$ to $17^{0} \mathrm{C}$ in the month of July (WeatherOnline, 2013). Leaves methanol extract of this plant is devoid of alkaloids, anthraquinones, flavonoids and phenolics (Ganjir et al., 2013), but leaves ethanol extract contains these four phytoconstituents (Venkataraman et al., 2013b). Ganjir et al. (2013) used the plant from medicinal germplasm garden of Regional Plant Resource Centre of Bhubaneswar while Venkataraman et al. (2013b) used the plant from coastal areas of district Tamil Nadu in India. Plant materials in the Regional Plant Resource Centre, with an aim of providing green lung to the inhabitants in the area (Regional Plant Resource Centre, 2013), were presumably less exposed to biotic and abiotic stresses than the plant which thrived in the coastal area. Maximum phenolic concentration contained in the plant, when harvested in the monsoon season at Sagar Island; in Digha Coastal Region, the harvest during the post- monsoon season yielded the maximum phenolic concentration. Furthermore, both phenolic and flavonoid contents in the plant are higher in Sagar Island than in Digha. These two regions are both transitional zone in-between sea and land (Mandal, 2013). However, Sagar Island is heavily surrounded with sea water while Digha coastal region is only 12 kilometers away from Subarnarekha River which can provide nutrients from agricultural runoff and lower seawater salinity in the area (Map data, 2013). The variability in phenolic compounds can be stress-related because the plants manufacture these compounds for protection under stressful conditions (Banerjee et al., 2013).

Phenolic compounds in plants have potent antioxidant activities. Antioxidants in humans play an important role in preventing adverse effects of oxidative stress. The main factors causing oxidative stress are the reactive oxygen species (ROS) which include the free radicals and the non-radical species (Jin et al., 2012). Oxidative damage due to overproduction of free radicals can lead to chronic diseases such as cancer, atherosclerosis, rheumatoid arthritis, diabetes, post-ischemic perfusion injury, myocardial infarction cardiovascular 
diseases, chronic inflammation, stroke and septic shock, aging and other degenerative diseases (Uttara et al., 2009). A balanced production of free radical and antioxidants is necessary for proper physiological function (Lobo et al., 2010). However, innate defense in the human body may not be enough; maintaining an adequate level of antioxidants to combat ROS required certain amounts of exogenous antioxidants (Rao et al., 2010). I. pes caprae with its broad spectrum pharmacological activity is a vital source of antioxidant phytochemicals (Manigaunha et al., 2010).

In the Philippines, I. pes-caprae (Linn.) Roth abundantly grows in ditches, canals and seashores. StuartXchange (2012) and Quisumbing (1978) identified the plant as "Bagasua" and reported pharmacological activities of the leaves such as escharotic to extirpate fungoid growth of ulcers and anodyne in rheumatism. Evidences on extensive investigation of I. pes-caprae (Linn.) Roth in the country are not yet available. The plant, named "lambayong" by the populace, abundantly flourished in the coastal area of the municipality of Clarin Misamis Occidental. However, anthropogenic activities specifically the expansion of resorts damaged and reduced the natural habitat of the plant which threatened its availability in the locality. In view of the substantial evidences on its pharmacologic and antioxidant activities, and the different results observed according to location and harvesting condition, this study aimed to conduct phytochemical screening and antioxidative potentials determination of the leaves of the wild and locally available I. pes-caprae (Linn) Roth. Extraction process used aqueous ethanol to remove the active components from the dried plant leaves. Sequential extraction using solvent of increasing polarity and the subsequent antioxidant test determined which solvent extracted most of the antioxidative material. The findings of the study can be used to introduce the curative potentials of the plant to the populace in the municipality of Clarin which is the source of the plant leaves sample. Awareness on the usefulness of the plant will provide enough reason to the public to protect it from extinction due to anthropogenic activities. Protecting the plant and its habitat provides two benefits, coastal preservation and availability of a potent herbal plant. Furthermore, the results shall serve as baseline data in exploring the usefulness of the locally grown plant in either fresh or processed material. 


\section{Materials and Methods}

Fresh leaves of "lambayong" were collected at the coastal area of Clarin, Misamis Occidental during summer time, and air dried for three weeks. Plant samples were cut into small pieces and crushed into fine powder using an osterizer. Seven hundred grams of powdered sample were soaked with $80 \%$ ethanol for 48 hours and subsequently filtered. Three hundred milliliters of the filtrate were allocated for the determination of phytochemicals while the remaining portion was concentrated using rotary evaporator. Twenty grams of the concentrated ethanol extract were freeze-dried and subjected to antioxidant tests. The remaining portion of the concentrated ethanol extract was subjected to exhaustive serial extraction (Tiwari et al., 2011) in the order of increasing polarity: hexane; ethyl acetate; and methanol. Separatory funnel was used in the separation of the extracts. The residual material left, after the separation of methanol serial extract, was found soluble in water and was considered the aqueous serial extract. The crude ethanol extract (CEE) and the serial extracts: hexane extract (HE); ethyl acetate extract (EAE); methanol extract (ME) and aqueous extract (AE) were subjected to antioxidant test.

Phytochemicals, namely: alkaloids, anthraquinones, steroids and triterpenes, flavonoids and leukoanthocyanins, saponins, and tannins and phenolic compounds were determined using the standard methods of Tiwari et al. (2011) and Maiti et al. (2011) with slight modifications. Wagner's and Mayer's tests were used for alkaloids; Borntrager's test was used for anthraquinones; Liebermann-Burchard test was used for unsaturated steroids and triterpenes; Froth test was used for saponins and Gelatin-salt block test and ferric chloride $\left(\mathrm{FeCl}_{3}\right)$ test were used for tannins and phenolic compounds (Tiwari et al., 2011). Shinoda test was used for flavonoids (Maiti et al., 2011).

Ferric Thiocyanate (FTC) assay (Rahmat et al., 2003) with slight modification was used in determining antioxidative potentials of the plant extracts. In this study, oleic acid was used in the lipid system instead of linoleic acid and ferrous sulphate $\left(\mathrm{FeSO}_{4}\right)$ in sulfuric acid $\left(\mathrm{H}_{2} \mathrm{SO}_{4}\right)$, instead of $\mathrm{FeCl}_{2}$ in hydrochloric acid $(\mathrm{HCl})$ in the peroxide detecting reagent. The assay mixture is a lipid system consisting of 2.0 $\mathrm{mg}$ of the extract/control in $2.0 \mathrm{~mL}$ of absolute ethanol; $2.0 \mathrm{~mL}$ of $2.52 \%$ oleic acid in absolute ethanol; $4.0 \mathrm{~mL}$ of $0.05 \mathrm{M}$ phosphate 
buffer ( $\mathrm{pH} 7.0$ ); and $2.0 \mathrm{~mL}$ of distilled water. The mixture was placed in an amber screw-capped bottle, mixed, and then incubated at $40^{\circ} \mathrm{C}$ until the termination of the activity. One hundred microliters of the assay mixture was withdrawn immediately after mixing for the zero day. This was added to the previously prepared mixture of $10.0 \mathrm{~mL}$ of $75 \%$ ethanol and $0.1 \mathrm{~mL}$ of $30 \%$ ammonium thiocyanate. To this mixture, $0.1 \mathrm{~mL}$ of $0.02 \mathrm{M} \mathrm{FeSO}_{4}$ in $\mathrm{H}_{2} \mathrm{SO}_{4}$ was added and mixed. Three minutes thereafter, absorbance was determined at $500 \mathrm{~nm}$. This procedure was repeated on the assay mixture every 24 hours for four days. The controls used were distilled water for the blank (for a negative control) and $\alpha$-tocopherol (vitamin E) and butylated hydroxyl toluene (BHT) for the standard (positive controls). Vitamin E and BHT were prepared in the same manner as the plant extracts.

The absorbance readings in FTC assay expressed the amount of ferric ion $\left(\mathrm{Fe}^{3+}\right)$ oxidized from ferrous ion $\left(\mathrm{Fe}^{2+}\right)$. The lipid peroxide resulting from the non-enzymatic oxidation of oleic acid in the lipid system oxidized the ferrous ion (Repetto et al., 2012). Ethanol used as the solvent in the lipid system, is a pro-oxidant. It promoted the lipid peroxide production. Addition of antioxidant into the mixture prevents the production of lipid peroxide (Kancheva \& Kasaikina, 2012). Vitamin E and BHT are both antioxidants that affect intermediate products in lipid peroxidation. Vitamin E, a primary antioxidant, prevents lipid peroxidation by converting lipid radicals into stable product. BHT, a secondary antioxidant, captures free radicals and terminates chain reaction for lipid peroxidation (Hamid et al., 2010). Absorbance readings determined the extent to which antioxidants prevented the formation of lipid peroxide. Higher absorbance readings indicated lesser extent of antioxidative activity while lower absorbance readings indicated greater extent of antioxidative activity.

\section{Results and Discussion}

Phytochemical screening of CEE of the dried I. pes-caprae (Linn.) Roth leaves revealed the presence of alkaloids, unsaturated steroids and triterpenes, flavonoids, and tannins and phenolic compounds; and absence of anthraquinones and saponins (Table 1). These are secondary metabolites, which play an important role in plant defenses and, in man, exhibit diverse physiological activities. These 
compounds can fall to any of the large chemical classes: alkaloids; terpenoids and phenolics (Freeman, 2008). Biosynthesis of these compounds has long been thought to be too costly for the plants in relation to resources expenditures and risk of intoxicating the plant itself. To lower this cost, plants opt to use the constitutive or induced defenses. Plants which are frequently or seriously damaged opt to invest in constitutive defenses while those which rarely attacked opt to invest in induced defenses (Wittstock \& Gershenson, 2002).

\section{Table 1. Results on phytochemical screening.}

\begin{tabular}{lll}
\hline \hline Phytochemical & Test used & Result \\
\hline Alkaloids & Wagner's test & positive \\
& Mayer's test & positive \\
Steroids and triterpenes & Liebermann-Burchard Test & positive \\
Saponins & Froth test & negative \\
Anthraquinones & Borntrager's Test & negative \\
Flavonoids & Shinoda test & positive \\
Tannins and phenolic compounds & Gelatin-salt block test & positive \\
& $\mathrm{FeCl}_{3}$ test & positive \\
\hline \hline
\end{tabular}

Alkaloids in plants, commonly act as bioprotective neurotoxins, which attacked the unique nervous system of the herbivores while remaining immune to the toxin (Scdardl, 2006). The presence of alkaloids in $I$. pes caprae (Linn.) Roth at Clarin signified that herbivores attacked the plant, which produced alkaloids to fight back. Existing studies also revealed similar results. De Souza et al. (2000) showed the presence of alkaloids in the aerial part of the plant, while Venkataraman et al. (2013a) and Parekh et al. (2012) detected these compounds in the plant leaves. However, Ganjir et al. (2013) and the StuartXchange (2012) both revealed the absence of these compounds in the plant leaves. Terpenoids protect plants by acting as toxins and feeding deterrents to herbivores and mammals (Vince \& Zoltan, 2011). Triterpenes, which belong to this group, has two subgroups, namely cardenolides and saponins. Positive results in steroids and triterpenes and a negative result in saponins tests signified the presence of cardenolides in I. pes caprae (Linn.) Roth leaves. The bitter taste of cardenolides protects the plant from herbivores and mammals (Vince \& Zoltan, 2011). Damage on plants by herbivores, induced cardenolide production (Agrawal, 2012). However, there was 
no evidence for a trade-off between constitutive and induced cardenolides across plant species (Rasmann et al., 2009). Results of this study confirmed the findings of De Souza et al. (2000), which revealed the presence of steroids and terpenoids in methanol extract from the aerial part of the plant and Ventakaraman et al. (2013a), which revealed the presence of terpenoids in the plant leaves ethanol extract. Conversely, the findings contradicted the studies of Ganjir et al. (2011) which revealed the presence of saponins in the plant leaves ethanol extract. Anthraquinones, flavonoids, tannins and phenolic compounds are some of the compounds constituting the phenolics. Plants produced this group of compounds mainly to fight against stress (Bhattacharya et al., 2010). This study revealed the presence of flavonoids and tannins and phenolic compounds in the I. pes caprae (Linn.) Roth leaves ethanol extract. Some flavonoids served as ultraviolet filters (Woo et al., 2000), insecticides, pesticides and piscicides while others exhibit an anti-estrogenic effect, which render the grazing animal infertile (Vince \& Zoltan, 2011). Tannins protect the plants from herbivores through their toxicity and astringency (Kimball \& Provenza, 2003). Exposure of plants to diverse types of attackers in the environment begets the responses which include the use of constitutive and induced phenolics affecting the susceptibility or resistance characteristics of the attacked plant (Lattanzio et al., 2006). Studies which revealed the presence of flavonoids in the aerial part of the plant (De Souza et al., 2000) and in the leaves (Venkataraman et al., 2013a; Parekh et al., 2012) also showed the presence of tannins in the leaves of the plant. These results contradicted in part the findings of Ganjir et al. (2011) which showed that plant leaves ethanol extract contained tannins but devoid of phenolics and flavonoids.

Presence of diverse phytochemicals in I. pes caprae (Linn.) Roth leaves collected at the coastal area, suggested exposure of the plant to herbivores, pathogens and various kinds of abiotic stresses (Mazid et al., 2011). Synthesis and accumulation of secondary metabolites occurred in plant for optimum protection (Kimball \& Provenza, 2003). This result is very similar to the studies of Venkataraman et al. (2013a) and Parekh et al. (2012) which also used plant samples from the coastal areas. However, these findings differ mainly from the study of Ganjir et al. (2013) which used plant samples from medicinal germplasm garden of Regional Plant Resource Centre 
of Bhubaneswar. Reasonably, wild I. pes caprae, which thrived in a coastal area, produced more secondary metabolites to survive than the cultivated plant in a controlled environment.

In FTC assay, five readings were made from zero day which was done immediately after the lipid system had been prepared, up to the fourth day. The production of peroxide in the negative control continued to rise while that of the positive controls, vitamin E and BHT, were consistently controlled (Figure 1). The absorbance readings of CEE were fluctuating between the positive and the negative controls. The result suggested that $\mathrm{CEE}$ prevented the formation of lipid peroxide, shown by the lower concentration of $\mathrm{Fe}^{3+}$. CEE exhibited antioxidative potential but of lesser extent than the positive controls. Being a crude extract, CEE contained all components from the dried leaves extractable with ethanol including non-antioxidants. Reasonably, the concentration of antioxidant in CEE was lower than the pure vitamin $\mathrm{E}$ and $\mathrm{BHT}$.

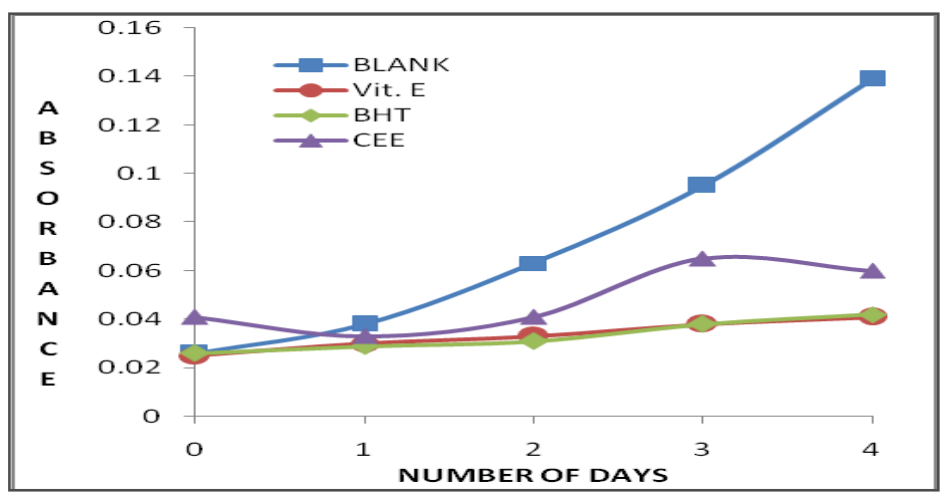

Figure 1. Antioxidative evaluation of the crude ethanol extract for four days.

Serial extraction using the solvents: hexane, ethyl acetate, methanol and water apportioned the phytochemicals of the I. pescaprae (Linn.) Roth into nonpolar, moderately polar, polar and most polar extracts respectively. The FTC assay of the serial extracts, HE, EAE, ME and AE showed varied results. The absorbance readings of $\mathrm{ME}$ and $\mathrm{AE}$ consistently followed the patterns of the positive controls, vitamin E and BHT, (Figure 2). This result revealed that both ME and $\mathrm{AE}$ prevented the formation of lipid peroxide, indicated by lower 
concentration of $\mathrm{Fe}^{3+}$, in almost the same extent as the positive controls. Except for the first reading, the absorbance readings of $\mathrm{HE}$ were fluctuating between the positive and the negative controls. This showed that the ability of HE to prevent the formation of lipid peroxide was lower than the positive controls. Distribution of the components in $\mathrm{CEE}$ into four serial extracts had concentrated the antioxidant in $\mathrm{ME}$ and $\mathrm{AE}$. This signifies that the antioxidants in I. pes-caprae (Linn.) Roth, possess predominantly polar character. Its extractability with water made I. pes-caprae (Linn.) Roth a potential source of affordable formulation for the relief of some ailments or to boast wellness. Using water instead of organic solvent will make the extract more compatible for human consumption.

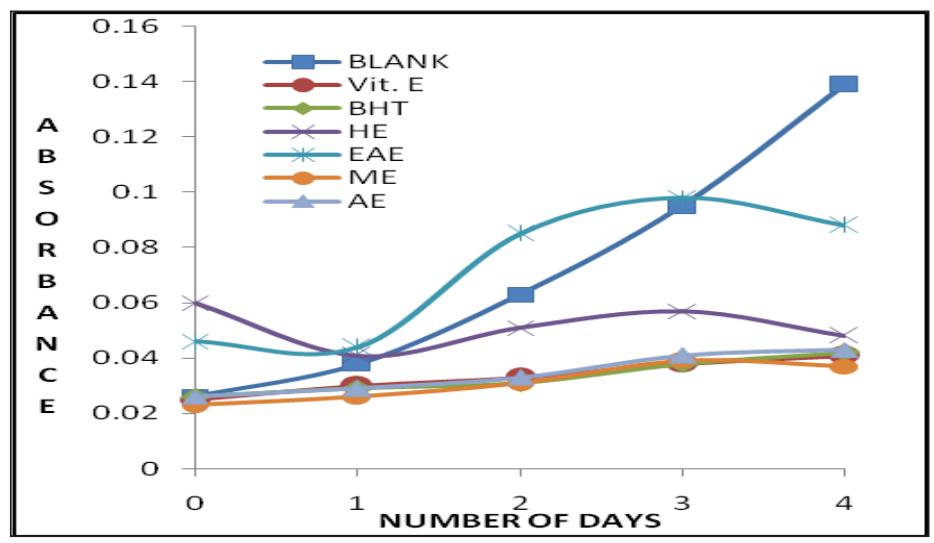

Figure 2. Antioxidative evaluation of the serial extracts for four days.

The results suggested that phytochemicals developed profoundly in I. pes-caprae (Linn.) Roth, which abundantly flourished in the municipality of Clarin, Misamis Occidental. The area can abundantly provide the plant material for further study specifically quantitation and elucidation of specific phytochemicals or other biochemical assay leading to the identification of a novel compound. 


\section{Conclusion and Recommendations}

Phytochemical screening of CEE revealed that wild I. pescaprae (Linn.) Roth which thrived in Clarin, Misamis Occidental possessed pharmacologically active components such as alkaloids, steroids and triterpenes, flavonoids, and tannins and phenolic compounds. FTC assay demonstrated the antioxidative potential of the plant which was more pronounced in methanol and water serial extracts. These results show that this plant, which abundantly grows in the locality, has the potential to treat different kinds of ailments.

Although FTC assay yielded useful information on antioxidative activity of the plant, further study is necessary before the material can be utilized by humans, to account digestion and metabolic activity. However, instead of serial extraction, individual extraction, using separate portions of the dried plant leaves, will be more applicable to ascertain which solvent shall be extracting most of the phytochemicals. Cytotoxic determination shall also be included considering that the plant is inedible.

\section{Acknowledgment}

Authors are grateful to Misamis University for funding this study and Mindanao State University-Iligan Institute of Technology for the utilization of laboratory facilities. The Natural Science Department of Misamis University is also acknowledged for the technical support.

\section{Literature Cited}

Agrawal, A. A., Petschenka, G., Bingham, R. A., Weber, M. G., \& Rasmann, S. (2012). Toxic cardenolides: chemical ecology and coevolution of specialized plant-herbivore interactions. New Phytologist, 194(1), 28-45.

Banerjee, D., Chakrabarti, S., Hazra, A. K., Banerjee, S., Ray, J., \& Mukherjee, B. (2008). Antioxidant activity and total phenolics of some mangroves in Sundarbans. African Journal of Biotechnology, 7(6), 805-810. 
Banerjee, D., Hazra, A. K., Chakraborti, S., Ray, J., Mukherjee, A., \& Mukherjee, B. (2013). Variation of total phenolic content, flavonoid and radical scavenging activity of Ipomoea pes-caprae with respect to harvesting time and location. Indian Journal of Geo-Marine Sciences, 42(1), 106-109.

Bhattacharya, A., Sood, P., \& Citovsky, V. (2010). The roles of plant phenolics in defence and communication during Agrobacterium and Rhizobium infection. Molecular plant pathology, 11(5), 705719. doi: 10.1111/j.1364-3703.2010.00625.x.

Bragadeeswaran, S., Prabhu, K., Rani, S., Priyadharsini, S., \& Vembu, N. (2010). Biomedical applications of beach morning glory Ipomoea pes-caprae. Int. J Tropical Medicine, 5(4), 81-85.

De Souza, M. M., Madeira, A., Berti, C., Krogh, R., Yunes, R.A., \& Cechinel-Filno, V. (2000). Antinociceptive properties of the methanolic extract obtained from Ipomoea pes-caprae (L.) R. Br. Journal of Ethnopharmacology, 69(1), 85-90.

Emendörfer, F., Emendörfer, F., Bellato, F., Noldin, V. F., Niero, R., \& Cechinel-Filho, V., (2005). Evaluation of the relaxant action of some Brazilian medicinal plants in isolated guinea-pig ileum and rat duodenum. J Pharm Pharmaceut Sci, 8(1), 63-68.

Freeman, B. C., \& Beattie, G.A. (2008). An overview of plant defenses against pathogens and herbivores. The Plant Health Instructor. doi: 10.1094/PHI-I-2008-0226-01.

Ganjir, M., Behera, D. R., \& Bhatnagar, S. (2013). Phytochemical analysis, cytotoxic and antioxidant potential of Ipomoea pes caprae (L) R. $\mathrm{Br}$ and Merremia umbellata (L.) H. Hallier. International Journal of Scientific \& Technology Research, 2(5), 80-83. 
Hamid, A. A., Aiyelaagbe, O. O., Usman, L. A., Ameen, O. M., \& Lawal, A. (2010). Antioxidants: Its medicinal and pharmacological applications. African Journal of Pure and Applied Chemistry, 4(8), 142-151.

Hill, K. (2001, October 24). Ipomoea pes-caprae. Smithsonian Marine Station at Fort Pierce. Retrieved from http://www.sms.si.edu/ irlspec/Ipomoea_pesCap.htm

Jin, L., Zhang, Y., Yan, L., Guo, L., \& Niu, L. (2012). Phenolic compounds and antioxidant activity of bulb extracts of six Lilium species native to china. Molecules, 17(8), 9361-9378.

Kancheva, V. D., \& Kasaikina, O. T. (2012). Lipid oxidation in homogeneous and micro-heterogeneous media in presence of prooxidants, antioxidants and surfactants. In A. Catala (Ed.). Biochemistry, Genetics and Molecular Biology. CC BY 3.0 license. doi: 10.5772/46021

Khan, M. M., Ahmad, F., Rastogi, A. K., Kidwai, J. R., Lakshmi, V., \& Bhakuni, D. S. (1994). Insulinogenic and hypoglycemic activities of Ipomoea pes-caprae. Fitoterapia, 65(3), 231-234.

Kimball, B. A., \& Provenza, F. D. (2003). Chemical defense and mammalian herbivores. USDA National Wildlife Research Center - Staff Publications, 236. Retrieved from http://digital commons.unl. edu/ cgi/viewcontent .cgi ?article=1230\&context= icwdmusdanwrc

Krogh, R., Kroth, R., Berti, C., Madeira, A. O., Souza, M. M., Cechinel-Filho, V., ... \& Yunes, R. A. (1999). Isolation and identification of compounds with antinociceptive action from Ipomoea pes-caprae (L.) R. Br. Die Pharmazie, 54(6), 464-6. 
Lattanzio, V., Lattanzio, V. M. T., \& Cardinali, A., (2006). Role of phenolics in the resistance mechanisms of plants against fungal pathogens and insects. Phytochemistry: Advances in Research, 23-67. Retrieved from http://www.trnres.com/ebook/uploads/ imperato/T_ 1231133597Imperato-2.pdf

Li, H., Wang, X., Li, Y., Li, P., \& Wang, H. (2009). Polyphenolic compounds and antioxidant properties of selected China wines. Food Chemistry, 112, 454-46.

Lobo, V., Patil, A., \& Chandra, N. (2010). Free radicals, antioxidants and functional foods: Impact on human health. Pharmacogsy reviews, 4(8), 118-126. doi: 10.4103/0973-7847.70902

Maiti, B. C., Kesari, A., \& Kumari, N. (2011). Phytochemical screening of crude powder and extracts of Mussaenda frondosa. Advances in Pharmacology and Toxicology, 12(2), 63-66.

Mandal, M., Dandapath, P. K., \& Bhushan, S. (2013). Digha Sankarpur littoral tract a geographical case study. International Journal of Humanities and Social Science Invention. 2(4), 46-54.

Manigaunha, A., Ganesh, N. \& Kharya, M. D. (2010). Morning glory: A new thirst in-search of de-novo therapeutic approach. International Journal of Phytomedicine, 2, 18-21.

Map data. (2013). Digha, West Bengal, India. Google Map. Retrieved from https://maps. google.com.ph/maps?hl=fil\&tab=wl

Mazid, M., Khan, T. A., \& Mohammad, F. (2011). Role of secondary metabolites in defense mechanisms of plants. Biology and Medicine, 3(2), 232-249.

Murugan, T., Albino Wins, J., \& Murugan, M. (2013). Antimicrobial activity and phytochemical constituents of leaf extracts of Cassia auriculata. Indian $J$ Pharm Sci, 75(1), 122-125. doi: 10.4103/0250-474X.113546 
Parekh, K. K., Patel, A. M., Modi, A. J., \& Chandrashekhar, H. R. (2012). Antioxidant and cytotoxic activities of few selected Ipomoea species. Pharmacologia, 3(9), 377-386.

Philippi, M. E., Duarte, B. M., Da Silva, C. V., De Souza, M. T., Niero, R., Cechinel Filho, V., \& Bueno, E. C. (2010). Immunostimulatory activity of Calophyllum brasiliense, Ipomoea pes-caprae and Matayba elaeagnoides demonstrated by human peripheral blood mononuclear cells proliferation. Acta Pol Pharm, 67(1), 69-73.

StuartXchange. (2012). Philippine Medicinal Plants: Bagasua. Retrieved from http://www.stuart xchange.com/ Bagasua.html

Pongprayoon, U., Baeckström, P., Jacobsson, U., Lindström, M., \& Bohlin L. (1992). Antispasmodic activity of beta-damascenone and E-phytol isolated from Ipomoea pes-caprae. PubMed, 58(1), 19-21.

Pongprayoon, U., Bohlin, L., Soonthornsaratune, P., \& Wasuwat, S. (2006). Antiinflammatory activity of Ipomoea pes-caprae (L.) R. Br. Phytotherapy Research, 5(2), 63-66. doi: 10.1002/ptr.2650050205

Quisumbing, E. (1978). Medicinal Plants in the Philippines. Manila: Katha Publishing Co. Inc.

Rahmat, A., Kumar, V., Fong, L. M., Endrini. S., \& Sani H. A. (2003). Determination of total antioxidant activity in three types of local vegetables shoots and the cytotoxic effect of their ethanolic extracts against different cancer cell line. Asia Pac J Clin Nut, 12 (3), 308-311.

Rajamoni, R. (2010). Analgesic effect of the aqueous extracts of Ipomea pes-caprae (L.) R. Br. in albino mice. International Journal of Biology and Biotechnology, 7(4), 433-438.

Ramanathan, T., Shanmugapriya, R., Thirunavukkarasu, P., \& Renugade, G. (2011). In-vitro antifungal activity of Ipomoea pescaprae (L.) R. Br. ethanolic flower extract. International Journal of Advances in Pharmaceutical Research, 3(1), 732 - 735. 
Ramanathan, T., Umamaheshwari, G., \& Shanmugapriya, R. (2012). Antioxidant and radical scavenging effect of Ipomoea pes-caprae Linn. R. Br. International Journal of PharmTech Research, 4(2), 848851.

Rao, K. S., Munjuluri, P. R., \& Keshar, N. K. (2010). In vitro antioxidant activity and total phenolic content of Mimusops elengi bark. Indian Journal Pharm Edu Res., 45(4), 317-323.

Rasmann, S., Agrawal, A. A., Cook, S. C., \& Erwin, A. C. (2009). Cardenolides, induced responses, and interactions between aboveand belowgroundherbivores of milkweed (Asclepias spp.). Ecology, 90(9), 2393-404.

Repetto, M., Semprine, J., \& Boveris, J. (2012). Lipid peroxidation: Chemical mechanism, biological implications and analytical determination. In A. Catala (Ed.). Biochemistry, Genetics and Molecular Biology. CC BY 3.0 license. doi: 10.5772/45943

Regional Plant Resource Centre. (2013). It brings the beauty of nature indoors. Department of Forest and Environment, Government of Odisha, India. Retrieved from http://www. rprcbbsr.Com/View /view_all_news.aspx\#

Schardl, C. L., Blakenship, J. D., Machado, C., \& Spiering, M. J. (2006). Alkaloid-making fungal symbionts. In L. Taiz \& E. Zeiger (Eds.). A companion to plant physiology (5th ed.). Retrieved from http //5e.plantphys.net/article. php?ch=\&id=37

Tiwari, P., Kumar, B., Kaur, M., Kaur, G., \& Kaur, H. (2011). Phytochemical screening and extraction: A review. Internationale Pharmaceutica Sciencia, 1(1), 98-106.

Uttara, B., Singh, A. V., Zamboni, P., \& Mahajan, R. T. (2009). Oxidative stress and neurodegenerative diseases: A review of upstream and downstream antioxidant therapeutic options. Current neuropharmacology,7(1), 65-74. doi: $10.2174 / 157015909787602823$ 
Venkataraman, N. D., Atlee, W. C., Prabhu, T. P., \& Kannan, R. (2013a). Anti-inflammatory Potential of ethanolic extracts from aerial Parts of Ipomoea pes-caprae (L.) R. Br using cotton pellet induced granuloma model. Journal of Applied Pharmaceutical Science, 3(7), 61-63.

Venkataraman, N. D., Atlee, W. C., Prabhu, T. P., Surya, G., Kannan, R., \& Nasar, I. S. (2013b). Evaluation of in-vitro anti-arthritic potential of aerial parts of Ipomoea pes-caprae (L.) $\mathrm{R}$. Br and establishment of its mechanism of action. Research Journal of Pharmaceutical, Biological and Chemical Sciences, 4(2), 15601565.

Vieira, D., Padoani, D., Soares, J., Adriano, J., Filho, V. C., de Souza, M. M., ... \& Couto, A. G. (2012). Development of hydroethanolic extract of Ipomoea pes-caprae using factorial design followed by antinociceptive and anti-inflammatory evaluation. Brazilian Journal of Pharmacognosy, 23(1), 72-78. doi.org/10.1590/S0102695X201200 5000126

Vince, O. \& Zoltan, M. (2011). Plant Physiology: Secondary metabolites in plant defences. Retrieved from http://www. tankonyvtar.hu/hu/tartalom/tamop425/0010_1A_Book_angol_ 01_nov enyelettan/ch03s05.html

Wani, M., Sarvar, F.A., Agrawal, J., Deshpande, J., Mathew, S., \& Khetmalas, M. (2012). Qualitative phytochemical analysis and antimicrobial activity studies of Gymnema sylvestre R. Br. Acta Biologica Indica, 1(1), 121-124.

Wasuwat, S. (1970). Extract of Ipomoea pes-caprae (Convolvulaceae) antagonistic to histamine and jellyfish poison. Nature, 225, 758. doi: $10.1038 / 225758 \mathrm{a} 0$

WeatherOnline. (2013). Sweden. WeatherOnline Ltd. Retrieved from http://www.weatheronline. co.uk/reports/climate/Sweden.htm. 
Weather Spark beta. (2012). Historical Weather for 2012 in Florianópolis, Brazil. Cedar Lake Ventures Inc. Retrieved from http://weatherspark. com/history/33416/2012/Florianopolis-San taCatar ina-Brazil

Wittstock, U., \& Gershenzon, J. (2002). Constitutive plant toxins and their role in defense against herbivores and pathogens. Current Opinion in Plant Biology. 5(4), 300-3007. doi: 10.1016/S13695266(02)00264-9

Woo, H., Kuleck, G. A., Hirsch, A. M., \& Hawes, M. (2000). The role of flavonoids as signal molecules in plant development. Plant Biology, 11 (12), 2303-2316. 